


\title{
Una novela hospitalaria: La cresta de Ilión, de Cristina Rivera-Garza
}

\section{A hospitable novel: La cresta de Ilión, by Cristina Rivera Garza}

\author{
Felipe A. Ríos Baeza \\ Universidad Anáhuac Querétaro, México \\ feliperios.ffyl@gmail.com
}

Resumen: A partir del concepto de hospitalidad propuesto por el filósofo francés Jacques Derrida, este ensayo pretende definir los rasgos más significativos de La cresta de Ilión (Tusquets, 2002), de la escritora mexicana Cristina Rivera Garza; novela recientemente reeditada (Random House, 2018) y que resulta pieza fundamental de su narrativa, ya que desde allí se irradiarán muchos asuntos singulares para sus obras posteriores. Si en Nadie me verá llorar (1999), primera novela de Rivera Garza, buena parte de las acciones acontecían en un recinto "hospitalario", La cresta de Ilión parece presentar cierta continuidad, al menos en lo que se refiere a los espacios de desenvolvimiento de la trama y a los personajes masculinos abrumados, pero el efecto performativo sobre la prosa misma de Rivera Garza se verá completamente transformado. Por lo tanto, en diálogo y en polémica con la crítica literaria que ha abordado este libro, se estudiará de qué manera un espacio literario recibe, de forma problemática, trazas de otros discursos, pensando este procedimiento de modo más deconstructivo que intertextual, ya que dicho modelo parece insuficiente para determinar el articulado de novelas como ésta.

Palabras clave: Cristina Rivera Garza, hospitalidad, performatividad, deconstrucción, género. 
Abstract: Starting from the concept of hospitality, proposed by French philosopher Jacques Derrida, this essay tries to define the most significant features of La cresta de Ilión (Tusquets, 2002), by Mexican writer Cristina Rivera Garza; a novel that was recently re-edited (Random house, 2018) and that has become a fundamental piece of her narrative, because it will irradiate many singular affairs to her subsequent works. If in Nadie me verá llorar (1999), which is Rivera Garza's first novel, most of the actions happened in a "hospital/hospitality" environment, La cresta de Ilión seems to have some continuity, at least in the spaces where the action takes place and the overwhelmed masculine characters, but the performative effect over Rivera Garza's prose is completely transformed. Therefore, in agreement and at the same time disagreement with previous critics of this novel, this essay will study the way in which a literary space receives, in a problematic way, traces of other rhetoric, thinking this procedure more deconstructive than intertextual, because this model seems insufficient to determine the articulated novels like this one.

Key words: Cristina Rivera Garza, Hospitality, Performativity, Deconstruction, Gender.

Recibido: 10 de octubre de 2018

Aceptado: 2 de febrero de 2019 http://dx.doi.org/10.15174/rv.v0i24.444

$C_{\text {Rivera Garza (Matamoros, 1964) se ha posicionado en el ac- }}^{\text {on una treintena de libros publicados la tamaulipea Cristina }}$ tual sistema literario mexicano como uno de sus nodos irradiadores más interesantes. Utilizo aquí "irradiador" en un sentido deliberado: tal y como lo reconocen los compiladores del libro Cristina Rivera Garza: Una escritura impropia. Un estudio de su obra literaria (1991-2014) (2015), pues si algo caracteriza a esta escritora es su capacidad de absorber y después proyectar y diseminar sus intereses privados como lectora. "Antes de escribir, hay que leer", marcan Cécile Quintana y Alejandro Palma en la introducción del mencionado volumen: "Desde su trabajo de tesis sobre el manicomio 
de La Castañeda hasta el retrato del México doliente de principios de siglo presentado en Los muertos indóciles, se responden y se articulan estos [...] enfoques" (Palma/Quintana, 2015: 8-9).

Crítica literaria, teatro, filosofía, narrativa, historia, política, estudios género o poesía son algunos de los discursos que Rivera Garza acoge en su espacio literario hospitalariamente (y destaco ese término porque a continuación se verá lo problemático que se vuelve en su narrativa), y que luego metaboliza para hacerlos parte de su singular eje creativo. Sin embargo, no se trata solamente de realizar una cita, una glosa o un comentario al modo intertextual más tradicional, sino de un mecanismo de creación que, si en su primera novela, Nadie me verá llorar (Tusquets, 1999) se evidenciaba con las marcas de cierto canon mexicano (Santa, de Federico Gamboa, por ejemplo) y de la historia del recinto psiquiátrico "La Castañeda", no será hasta La cresta de Ilión (Tusquets, 2002; Random House, 2018) que este rasgo distintivo de su narrativa dé toda su medida. Dicho característica la reconoceremos, aquí, como hospitalidad.

Con una intertextualidad tradicional me refiero, por supuesto, al modo genettiano de entender el asunto, que ha dominado los estudios literarios como el último de los bastiones estructuralistas que aún conllevan cierta utilidad. Recordando:

Defino la intertextualidad, de manera restrictiva, como una relación de copresencia entre dos o más textos, es decir, eidéticamente y frecuentemente, como la presencia efectiva de un texto en otro. Su forma más explícita y literal es la práctica tradicional de la cita (con comillas, con o sin referencia precisa); en una forma menos explícita y menos canónica, el plagio [...], que es una copia no declarada pero literal; en forma todavía menos explícita y menos literal, la alusión, es decir, un enunciado cuya plena comprensión supone la percepción de su relación con otro enunciado al que 
remite necesariamente tal o cual de sus inflexiones, no perceptible de otro modo (Genette, 1989: 10).

También, en algún grado, es posible leer el modo en que Cristina Rivera Garza tiene de esquejar en su escritura estas resonancias textuales anteriores desde la teoría alemana de la intertextualidad (pienso, por ejemplo, en la noción de komplexion de Renate Lachmann, ${ }^{1}$ un intento por articular un enfoque de este tipo pero desde la hermenéutica de la recepción). No obstante, si bien este "mapa" de citas, plagios y alusiones se ha superpuesto sobre los textos para marcar co-presencias efectivas, a la hora de interpretar proyectos contemporáneos como los de Roberto Bolaño, Enrique Vila-Matas, Mario Bellatin, César Aira y de la misma Rivera Garza, parece haberse quedado solamente en el campo del reconocimiento de elementos, diciendo en realidad poco de la naturaleza e identidad de textos que, como La cresta de Ilión, van más allá de

${ }^{1}$ Según afirma el autor alemán, en "Niveles del concepto de intertextualidad", resulta de vital importancia analítica "distinguir la intertextualidad intencional, que organiza la superficie del texto, de una intertextualidad latente que no perturba la superficie del intratexto y, sin embargo, determina la constitución del sentido, y es cuestión de distinguir esa intertextualidad de la producción de la intertextualidad de la recepción, que desde siempre fue un hallazgo de la estética de la recepción. En última instancia, se debería resolver el problema de la conglobación [Komplexion] del sentido, al que todas las tentativas analíticas parecen acercarse. En procedimientos como el almacenamiento de textos ajenos o elementos de textos ajenos en el texto actual (en calidad de cita, alusión, reminiscencia, etc.) o el cruce y acoplamiento, uno sobre otro, de un gran número de textos ajenos que pertenecen a diferentes poéticas (heterogeneización, bricolage) o la re-escritura y "contra"-escritura de un conocido texto como réplica, contrafactura, parodia, etc., no se trata ni de la evocación de un beatífico mundo de tradición literaria, ni de la demostración de una imborrable formación, que es hundida como cita en el texto, sino de la explosión semántica que ocurre en el contacto de los textos, de la producción de una diferencia estética y semántica” (Lachmann, 2004: 17). 
la sencilla identificación de hipotextos anteriores; traspasando, incluso, a un lector como polo de recepción que "conglobaría" dicho almacenamiento de textos ajenos en los textos que está revisando (para apartarnos, también, no sólo de Genette sino de Lachmann). Libros como éste que nos ocupa, o Bartleby y compañia, La literatura nazi en América, El libro uruguayo de los muertos o El congreso de literatura, marcan otro orden de cosas dentro del campo de la transtextualidad literaria: son una suerte de casas abiertas que esperan bajo otras condiciones, que no son simplemente la "modificación intertextual" o la "explosión semántica", a sus visitantes.

En La hospitalidad, el filósofo francés Jacques Derrida señala:

Quiero ser dueño en mi propia casa (ipse, potis, potens, dueño de casa) [...] para poder recibir en ella a quien quiero. Comienzo a considerar como extranjero indeseable, y virtualmente como enemigo, a quienquiera que invada mi "propio-hogar", mi ipséité, mi poder de hospitalidad, mi soberanía de anfitrión. Ese otro se vuelve un sujeto hostil del que corro el riesgo de volverme rehén (Derrida, 2000: 57).

Sobre este concepto complejo y polisémico de la hospitalidad pivotará una característica propiamente "riveragarciana", que explota en esa segunda novela y que se extiende hasta Alli te comerán las turicatas y Habia mucha neblina o humo o no sé qué, de 2013 y 2016 respectivamente: el encuentro con el otro nunca se da sin el fenómeno de la invasión. Para este ensayo se aprovechará, entonces, el marco de la deconstrucción de Derrida para definir el modo en que un espacio literario recibe, de manera problemática siempre, trazas de otros discursos. De esta manera se pretende, también, establecer un diálogo y a la vez una polémica con la crítica literaria a anterior que, me parece, ha visto de un modo sencillamente intertextual (francés o alemán) la presencia de la voz de Amparo 
Dávila en La cresta de Ilión. Y es que hay que tener en cuenta un asunto inicial: si en Nadie me verá llorar buena parte de las acciones acontecían en un recinto hospitalario, en su segunda obra parece presentar cierta continuidad, al menos en lo que se refiere a los espacios de desenvolvimiento de la trama y a los personajes masculinos abrumados, pero el efecto performativo sobre ellos y sobre la prosa de Rivera Garza se verán completamente transformados.

\section{Líneas críticas (o la acogida de un extranjero en el hogar)}

En un entorno siniestro, que incluye un hospital, complejos urbanos claustrofóbicos y una casa a orillas del mar, un médico recibe la visita de una mujer misteriosa y de una antigua amante, quienes lo involucrarán en una serie de eventos donde toda certeza (su trabajo, su sanidad mental, su vínculo con el pasado e incluso su masculinidad) se pondrá en tela de juicio. ${ }^{2}$ Tal como lo explica la ensayista Maryse Renaud: "el reto al cual se halla confrontado el lector de La cresta de Ilión implica la aceptación de nuevos códigos y un esfuerzo de abstracción, o por decirlo de otro modo, la comprensión de la dimensión metanarrativa que habrá de revestir la novela” (Renaud, 2012: párr. 3).

${ }^{2}$ Adriana González Mateos es una de las primeras en señalar que, según el foco genérico con el que se lea (mujeres y hombres) la novela puede pasar como una pieza de humor perverso o como un relato de franco terror: "La pesadilla incluye espectaculares fantasías de castración, momentos de genuina paranoia, guiños al espíritu tutelar de Foucault, cuyas ideas dan a la narración muchos momentos interesantes, además de sugerir el ambiente claustrofóbico e inquietante del hospital. Como ciertas pesadillas, la novela puede ser muy divertida para quienes la presencian sin estar atrapadas en ella: para unas pocas lectoras (como diría Borges) que incluso podrían ser de sexo masculino. Ellas (o ellos) se van construyendo y consolidando a partir de ciertas claves textuales hábilmente colocadas a lo largo de la narración" (González Mateos, 2003: 341). 
El trabajo de vasos comunicantes entre esta novela y la obra de Amparo Dávila ha sido el factor central que ha ocupado hasta ahora a buena parte de la crítica (Cf. Zaca Guevara, 2005; Mercado, 2007), pero me parece que, en definitiva, lo esencial de $L a$ cresta de Ilión es la recuperación en clave literaria de esa noción que problematizara Derrida al alero de sus lecturas de Emmanuel Lévinas, y como respuesta a algunas tesis de Jürgen Habermas. En una entrevista, Derrida dejó dicho que:

La hospitalidad, en el uso que Lévinas hace de este término, no se reduce simplemente, aunque también lo sea, a la acogida del extranjero en el hogar, en la propia casa de uno, en su nación, en su ciudad. Desde el momento en que me abro, doy, "acogida" - por retomar el término de Lévinas- a la alteridad del otro, ya estoy en una disposición hospitalaria. Incluso la guerra, el rechazo, la xenofobia implican que tengo que ver con el otro y que, por consiguiente, ya estoy abierto al otro. El cierre no es más que una reacción a una primera apertura. Desde este punto de vista, la hospitalidad es primera. Decir que es primera significa que incluso antes de ser yo mismo y quien soy, ipse, es preciso que la irrupción del otro haya instaurado esa relación conmigo mismo. Dicho de otro modo, no puedo tener relación conmigo mismo, con mi "estar en casa”, más que en la medida en que la irrupción del otro ha precedido a mi propia ipseidad (Derrida, 1997: párr. 8).

Estos planteamientos se cristalizarán en libros como Canallas. Dos ensayos sobre razón, Políticas de la amistad y sobre todo el citado La hospitalidad, donde, entre otros asuntos, Derrida somete a deconstrucción el asunto de la extranjería, la migración e incluso la cuestión judía de la aceptación de aquel "que vendrá", desprendidos, todos ellos, de la relación con el otro. Lo que interesa para este estudio literario es lo siguiente: al hablar de hospitalidad, Derrida 
propone que al momento de asumirse como "hospitalario", en el plano performativo de la acción se puede dar tanto una condición de posibilidad como de imposibilidad. Lo posible es reconocido como lo calculable, lo esperado, algo que para la recepción (del texto o del sujeto) ya estaba de antemano previsto debido a que existe la ilusión de un límite, una barrera o frontera que ayuda a discernir qué "acontecimientos" (extranjeros, textos, fenómenos, etc.) son capaces de entrar y cuáles no en alguna estructura familiar o conocida. Sin embargo (y estos adversativos, como se sabe, son fundamentales en la deconstrucción), lo imposible "no es lo que yo puedo remitir indefinidamente: se anuncia a mí, cae sobre mí, me precede y me sobrecoge aqui ahora, bajo la forma de una inyunción que no espera en el horizonte, que yo no veo venir, que no me deja en paz, ni me autoriza nunca a remitir más adelante" (Derrida, 2005: 123). Por tanto, lo imposible anula la soberanía de cualquier estructura, la infiltra y la violenta. En otras palabras, la posibilidad de un acontecimiento está constantemente asediada por una marca, un grama anterior: la de su imposibilidad, la de la incertidumbre de que el establecimiento de dicha frontera se vea vulnerada, dejando las voluntades de hacer "intertexto" en un plano superficial debido a que se trata de un mecanismo iterativo que precede a todo sujeto y a todo texto.

Aunque Derrida lo enuncie en un plano figurado, esta "acogida de un extranjero en el hogar" (esto que "cae sobre mî", contraviniendo, pues, la idea amable de horizonte hermenéutico) aparece como una recurrencia literal en La cresta de Ilión. Este médico sin nombre trabaja en un sanatorio situado a orillas del mar, el Hospital Municipal Granja del Buen Reposo, cercado por dos ciudades: La Ciudad del Norte y La Ciudad del Sur. La dirección de dicho Hospital le ha proporcionado al médico una casa con vista al mar, en la cual, en mitad de una noche de tormenta, lee un libro y espera a una mujer (posible), a la que llama La Traicionada -"Si 
me decido a llamarla la Traicionada no es con el afán de mofa o indiferencia. Lo hago porque éste es un apelativo que ella misma ha utilizado para hacer referencia a su relación conmigo" (Rivera Garza, 2002: 21)-. No obstante, quien se aparece en su puerta es otra mujer (imposible), delgada, de ojos enormes y escrutadores. El médico se paraliza de miedo y fija su atención en el hueso derecho de su pelvis, asunto que en un comienzo parecerá una extravagancia pero que luego, para el derrotero de los personajes y el mismo planteamiento general de Rivera Garza, resultará un evento fundamental. "Soy Amparo Dávila" (2002: 15), dice la mujer inesperada. "Te conozco de cuando eras árbol. De aquellas épocas" (2002: 19).

Desde el epígrafe que abre el libro, llamado "Invitación primera" y tomado del cuento "El patio cuadrado", ${ }^{3}$ La cresta de Ilión se presenta como una novela que asume la literatura de Amparo Dávila, y en especial el volumen de relatos Árboles petrificados (1977) más allá de la mera intertextualidad. Si bien algunos trabajos previos han examinado la absorción y transformación de la narrativa de Dávila en la de Rivera Garza con nociones posmodernas, ${ }^{4}$ creo

3 “- ¿Pero qué hacen los libros dentro de la piscina —le pregunté sorprendi$\mathrm{da}-$. ¿No se mojan?

—Nada les pasa, el agua es su elemento y ahí estarán bastante tiempo hasta que alguien los merezca o se atreva a rescatarlos.

— ¿Y por qué no me saca uno?

— ¿Por qué no va usted por él? —dijo mirándome de una manera tan burlona que me fue imposible soportar.

—Por qué no? —contesté al tiempo en que me zambullía en la piscina” (Dávila, 2001: 16-17).

${ }^{4} \mathrm{Al}$ respecto, puede consultarse el artículo "La cresta de Ilión: lo fantástico posmoderno" de Verónica Saunero-Ward: "Como texto postmoderno es autorreferencial y metaficcional, no se remite a la realidad, sino que se basa en su propia ficcionalidad. Sus personajes no llevan nombre ni características que permitan en la lectora la ilusión de la verosimilitud [...]. Sin embargo, resta el elemento 
que el asunto, finalmente, se desborda de esos anteriores marcos referenciales. Como opina Christopher Domínguez Michael: "El motivo literario de La cresta de Ilión es [Amparo] Dávila. Escribo motivo y no personaje, pues Rivera Garza hizo de Dávila, de sus textos, de sus fotografías en las cuartas de forros, de su leyenda (si es que la tiene) una potencia” (Domínguez Michael, 2012: 111).

Amparo Dávila funciona, efectivamente, como un motivo y no un personaje: una presencia invasora, irritante, desestabilizadora, no sólo para el protagonista cambiante y huidizo, sino para la propia prosa de la tamaulipeca que se ve "invadida" por la de la zacatecana. Podría hablarse, en este sentido, no tanto de "presencias efectivas de un texto en otro", según la lección archisabida de Julia Kristeva, ${ }^{5}$ sino de la ocupación, a un modo deconstructivo, que los textos de la autora de Árboles petrificados perpetran en la historia de la autora de La cresta de Ilión.

En relación con dicha ocupación, María Reyna Zaca Guevara comenta que el epígrafe de los libros flotando en la piscina tiene la función:

del deseo que se traduce en el deseo de ofrecer una visión alternativa de la realidad desde una perspectiva formal (el jugar con la referencialidad del lenguaje) y sociocultural (la disolución de las características genéricas). Es decir, si el lector desconociera la existencia de Amparo Dávila, escritora mexicana, se perdería la dimensión metaficcional de La cresta de Ilión, pero persistirían, en la novela, la ambigüedad entre la realidad y la irrealidad, la ambigüedad en la identidad de los personajes y en el género de los mismos, todas particularidades que refuerzan el carácter fantástico de la obra. Pero si se la lee en toda su intertextualidad, la novela se enriquece por la complejidad de realidades que la autora es capaz de entretejer y el lector emprende la aventura de armar el rompecabezas o de explorar el laberinto que representa la novela" (2006: 175).

${ }^{5}$ Para mayor atención al procedimiento intertextual, puede consultarse el texto clásico de Julia Kristeva, "Bajtin, la palabra, el diálogo y la novela” (1981). 
de orientar decididamente el texto nuevo (la novela) hacia los cuentos de Amparo Dávila. Pero además, el fragmento tomado de "El patio cuadrado" señala otra posible interpretación: el discurso de La cresta de Ilión sugiere, en efecto, que la persona de quien proviene la voz narrativa ha aceptado el reto de "zambullirse" en el universo de los cuentos de Amparo Dávila porque se atreve a rescatarlos (Zaca Guevara, 2005: 62).

En efecto, inicialmente parece un rescate: en el nivel de la diégesis, el médico le da refugio en su casa a una mujer que se identifica como Amparo Dávila (personaje); mientras que en el nivel de la escritura, o lo que Wolfgang Iser reconoció como "polo artístico", 6 Rivera Garza le abre la puerta y cobija la prosa de Amparo Dávila (autora). En ambos casos, se tendrá al interior de las estructuras (la "casa", la "escritura personal") un elemento que terminará por desestabilizarlas y ocuparlas totalmente, bajo la lógica de la imposibilidad hospitalaria derridiana.

Tanto la enunciación de Cristina Rivera Garza como la tranquilidad del personaje principal se alterarán de manera considerable. En el primer caso, La cresta de Ilión se desflecará en un discurso cada vez más confuso, fragmentario, más referencial y alusivo no sólo a Árboles petrificados, sino también a Música concreta (1964) y Muerte en el bosque (1985). En el segundo, la irrupción de Amparo como invasora en una vivienda marcada, por un lado, por lo

6 "La obra literaria posee dos polos que se podrían denominar el polo artístico y el polo estético; el polo artístico designa al texto creado por el autor y el polo estético designa la concretización efectuada por el lector. De una polaridad así resulta que la obra literaria no es exclusivamente idéntica ni con el texto ni con su concretización; ya que la obra es más que e1 texto, debido a que aquella gana vida solo en la concretización y esta, a su vez, no es totalmente libre de los planes que el lector introduce en ella, aun cuando tales planes sean activados bajo las condiciones del texto" (Iser, 1987: 122). 
masculino (al menos en un principio, el protagonista se identifica con una rigidez genérica y sexual) y, por otro, por lo cientifico (es médico) provocará que ambos focos performativos en el sujeto comiencen a fracturarse, impidiéndole, por tanto, aprehender la historia en la que se ha involucrado desde su anterior y rígida perspectiva de "hombre razonable".

Es la relación con ese otro -el otro "mujer", el otro "Amparo Dávila"- la que terminará por configurar la ipseidad declarada por Derrida, tanto en el enunciador de La cresta de Ilión como en el médico. "[C]uando conocí a Amparo Dávila conocí el deseo” (Rivera Garza, 2002: 18) comenta el narrador, para luego agregar: "Pero he aquí una confesión con cada una de sus vocales y consonantes: le tuve miedo" (19). Como desarrolla Derrida, la identificación y recepción del otro en ambientes de aparente autonomía, como el hogar o la identidad personal, lleva a la estupefacción por una certeza soberana: en la verdadera hospitalidad, en la real relación de anfitrión y huésped, se está en el reconocimiento, incluso, de la posibilidad de que el extranjero expulse de su casa a quien lo ha recibido (no por voluntad, sino por la propia esencia de la ley hospitalaria):

No existe hospitalidad.

Andamos. Nos desplazamos: de transgresión en transgresión, pero también de digresión en digresión. Qué significa ese paso excesivo [pas de trop], la transgresión si, para el invitado tanto como para el visitante, el pasaje del umbral sigue siendo siempre un paso de transgresión? ¿Si debe incluso seguir siéndolo? ¿Y qué significa ese paso sesgado [pas de coté], la digresión? ¿Adónde llevan estos extraños pleitos de hospitalidad? ¿Esos umbrales interminables, por lo tanto infranqueables, y esas aporías? Todo ocurre como si fuéramos de dificultad en dificultad. Mejor o peor, y más gravemente, de imposibilidad en imposibilidad. Todo ocurre como si 
lo imposible fuera la hospitalidad: como si la ley de hospitalidad definiese esta imposibilidad misma, como si sólo se pudiese transgredirla, como si la ley de la hospitalidad absoluta, incondicional, hiperbólica, como si el imperativo categórico de la hospitalidad ordenase transgredir todas las leyes de la hospitalidad, es decir, las condiciones, las normas, los derechos y los deberes que se imponen a los huéspedes, a aquellos o a aquellas que dan como a aquellos o a aquellas que reciben la acogida. Recíprocamente, todo ocurre como si las leyes de la hospitalidad consistiesen, al marcar límites, poderes, derechos y deberes, en desafiar y en trasgredir la ley de la hospitalidad, la que ordenaría ofrecer al recién llegado una acogida sin condición (Derrida, 2000: 79-81).

De esta forma, los niveles descritos, el del narrador y el del personaje, se emparentarán por las dinámicas de lenguaje en la que los personajes ingresan. En un momento el médico afirma: "Soy un hombre al que se le malentiende con frecuencia. Supongo que eso se debe a mi desorden verbal" (Rivera Garza, 2002: 20). No obstante, dicho "desorden verbal" opera como un sistema bastante organizado que gobierna los primeros compases de la novela y el entendimiento del mundo del narrador. Como comenté párrafos atrás, a quien el hombre espera en esa noche de tormenta es a una mujer que ha traicionado, para una posible reconciliación. Pero, tras la llegada de Amparo Dávila, las causas de dicha traición y los antecedentes de la relación con ella se manejarán de manera elíptica y quedarán en suspenso para el lector. Lo que se sabe es que "La Traicionada" viene enferma de algo que se califica ambiguamente como la "epidemia" y que, más adelante, se relacionará con la desaparición - "La desaparición es una condición contagiosa"- (2002: 30).

Tanto los personajes femeninos de la novela y la propia prosa de Amparo Dávila parecen aquejados de dicha "enfermedad", por 
lo que desean combatir el olvido haciéndose presentes en el contexto actual. Sin embargo, para ello requieren "hacerse espacio" en un entorno que las tiene, a priori, distanciadas (se trata de una ex-amante y una ex-escritora, prefijos que las ubican en el presente como apenas una sombra de la identidad que tuvieron en el pasado). Ésta es la primera exclusión explícita: no será el hombre, en su calidad de médico, quien se dedique a cuidarla, sino la intrusa. Entre ambas mujeres se establecerá una complicidad secreta que las llevará, luego, a compartir cama y un idioma secreto incluso, lo que dejará al médico en una posición de marginalidad en esta historia. Al parecer, la real trama de La cresta de Ilión es la que se urde en esa habitación que era, y ya no es, la del protagonista, en una casa que también era, y ya no es, la suya. Y si el narrador no es capaz de penetrar en dicho cuarto y conocer de qué va la historia, tampoco lo hará el lector real.

Ésa parece ser una de las expresiones máximas del trabajo hospitalario en la novela de Rivera Garza: un libro que debería desarrollar en profundidad el vínculo entre una mujer verdadera o falsamente traicionada y otra mujer que se identifica verdadera o falsamente como Amparo Dávila, pero que deja fuera de ese vínculo tanto a quien enuncia la narración como a quien la recibe. De este modo, el médico buscará encontrar complicidad con el lector, no sólo tomando la opción de, al igual que él, bordear esa historia, hacerse conjeturas, conocer la parcialidad de los hechos, sino optando por resistirse a desaparecer luego de lo que podría identificarse como la "primera parte" del libro, cuando la irrupción abrupta de las dos mujeres se vuelve una ocupación de facto: "Esa mañana pues, gracias a mi trabajo, pude escapar de la rutina que Amparo ya había creado en mi casa. Y aunque mi logro sólo duraba ocho horas en cinco días de la semana, lo festejé con orgullo secreto y anónimo. Amparo Dávila, ya había tomado yo la decisión, no me desaparecería. Nunca lo lograría" (2002: 29). 


\section{Un idioma mojado: hacia la indiferenciación de los géneros}

Como se comentaba, ni lector ni narrador pueden, inicialmente, entrar en el círculo hermético que las mujeres han creado para sí, al que han blindado con el más férreo de los muros: un idioma personal. En un principio, la única opción de sobrevivir en esa marginalidad es convirtiéndose en un espía:

El sonido de los vocablos era insoportablemente melodioso, casi dulce. Y había una repetición intrigante de la que me di cuenta como al tercer día de mi espionaje. Se trataba de un sonido parecido a la sílaba "glu". La repetían incesantemente y, al hacerlo, parecían replicar el eco de la lluvia, el momento en que una gota de agua cae pesada y definitiva sobre la corteza del mar [...]. Cada que las oía platicar me hundía en una rabia inconmensurable, paralizadora. No podía hacer nada contra su lenguaje. No podía entrar en él (2002: 40).

La construcción de un idioma privado con tales reminiscencias acuáticas -"Glu hiserfui glu trenji fredso, glu, glu-glu” (2002: 119)- hace ingresar en la historia invisible de las mujeres al menos dos asuntos esenciales para la novela. En primer lugar, que la desaparecida prosa de la autora Amparo Dávila, según lo demostraba el epígrafe de Árboles petrificados, ha quedado en el fondo del agua - ¿Pero qué hacen los libros dentro de la piscina?”- (Dávila, 2001: 16) y por tanto el único modo de recuperarla, de darle hospitalidad, es desentrańando las oraciones mojadas de los delgados y ahora apelmazados volúmenes que escribió. En segundo lugar, que la construcción de ese lenguaje se conecta con una de las subtramas más interesantes: la del enfermo subversivo Juan Escutia, relatada por el personaje de la primera Amparo Dávila, cuando el médico 
intenta drogarla con morfina para saber los reales propósitos de su estancia en la casa.

En una de las pocas conversaciones coherentes, la mujer le confiesa que su desaparición en tanto escritora se debió a una conspiración dirigida por uno de los enfermos, Juan Escutia, quien alguna vez fuera acogido en el Hospital Granja del Buen Reposo y donde dejó un manuscrito robado de Dávila. El sujeto, descrito como "un nuevo Prometeo", organizó en el pasado una rebelión de los enfermos terminales contra los médicos con el fin de que estos, si no tenían la intención de sanar a los pacientes, al menos les enseñaran a bien morir: "Los conminaba a morir con dignidad, a exigir un trato justo, a demandar por lo menos un ataúd, a abolir la fosa común” (Rivera Garza, 2002: 46). A su modo, Escutia también es un personaje que lucha contra la desaparición y el olvido, pero los enfermos, deseosos de descansar lo más pronto posible, se revuelven contra él y lo empujan a un abismo de arrecifes $^{7}$ (una versión transfigurada de la caída "real" del niño héroe en 1847): "Los tullidos, los purulentos, los sin brazos o sin cabello, los estériles, todos los demás se levantaron de sus catres, que eran en realidad sus tumbas temporales, para obligarlo a saltar" (2002: 46-47).

Tras las descripciones de Juan Escutia como este Prometeo heroico e idealista, la mujer se centra en lo que verdaderamente le importa: el manuscrito que le han arrebatado y que parece la causa de su parálisis escritural: "Estoy segura de que ahí se fueron los

${ }^{7}$ En cierta medida, y atisbando un posible estudio tematológico de la literatura mexicana contemporánea, las descripciones que hace Cristina Rivera Garza de la Granja del Buen Reposo recuerdan a las del "salón de belleza" al que van a morir los enfermos en la novela homónima de Mario Bellatin: "Puede parecer difícil que me crean, pero ya casi no individualizo a los huéspedes. Ha llegado un estado en el que todos son iguales para mí. Al principio los reconocía. Incluso una que otra vez llegué a encariñarme con alguno. Pero ahora no son más que cuerpos en trance hacia la desaparición" (Bellatin, 1999: 33). 
códigos de mi memoria, de mis palabras. De todas mis palabras", confiesa. "No he vuelto a escribir desde entonces" (2002: 47). El modo de recuperarlo, aunque fragmentariamente, es hablando como un ahogado, hablando como hablaría una suerte de figura enaltecida que, aunque conscientemente empujada al asesinato en la realidad, ha tomado la forma de un referente ideal para comunicarse. Asimismo, la historia de Juan Escutia opera también como una advertencia de lo que puede pasarle al médico si se entromete tanto con la Traicionada como con Amparo Dávila, la cual, se descubre pronto, es una impostora, una emisaria de una Amparo Dávila que vive, incluso después de muerta, en una de las ciudades colindantes.

De esta manera, en La cresta de Ilión el ser mujer, que se anuncia constantemente, va a fluctuar en varios niveles. ¿Cómo asegurarse en este relato de que, en términos ontológicos, se es hombre o se es mujer? ¿Cómo estar seguro de que, investido por alguno de los dos géneros, no se está actuando como el otro en ciertos momentos, más allá de lo que el psicoanálisis tradicional reconoce bajo la premisa de la "preferencia de objeto"? Para referirse a sus colegas del hospital, el médico establece una diferenciación clara de opuestos que, por supuesto, va más allá de lo biológico-natural:

[En el hospital] evité hablar con los hombres porque su estatura de menor rango los volvía resentidos y, luego entonces, mezquinos; y me concentré en entablar conversación con las dos mujeres que cuidaban de nuestros documentos históricos. Porque eran mujeres, su rango menor, claramente inferior comparado con el mío, no les provocaba resentimiento alguno sino, por el contrario, secretos deseos arribistas que, a veces, se mezclaban con extrañas urgencias sexuales (2002: 48). 
En este pasaje parece establecerse la estructura genérica de comportamiento que tendrán tanto hombres como mujeres, según la ideología del médico, colindante con aquello que los estudios de género han bautizado como patriarcado o falogocentrismo. Los primeros, al habérseles reprimido un profundo deseo de dominación, tendrán al resentimiento y la mezquindad como ejes de su comportamiento, características colindantes e incluso causales. No obstante, las segundas, ya acostumbradas a una condición de subalternidad, se comportarán paradójicamente, expresando arribismo y urgencias sexuales. Es decir, por una parte, actuarán ostentando el mínimo privilegio social que han podido alcanzar (como las centinelas del archivo en donde, efectivamente, se encuentra el manuscrito de Amparo Dávila) y estableciendo con ello un círculo discriminatorio; pero, por otra, enviando señales constantes de que desean acercarse a otro y ser poseídas (lo que efectivamente termina sucediendo cuando, en un pacto perverso, las mujeres descritas violan las reglas del hospital haciendo pasar al médico al archivo secreto de pacientes a cambio de una noche de dominación sexual).

"Yo sé tu secreto" (2002: 55), le espeta una noche Amparo Dávila al médico en su casa. "Yo sé que tú eres mujer" (2002: 56). Luego de que, páginas atrás, el propio protagonista determinara lo que equivale ser mujer, se descubre un asunto cuando menos inquietante: debido al modo arribista en que, primero, se refiere a los habitantes de su ciudad, a sus pacientes y luego a las mujeres que acoge y, en segundo lugar, al hecho de que el miedo por la Amparo invasora se le vuelve una urgente demanda sexual, entonces convendría pensar que esta hospitalidad radical no sólo saca, materialmente, al dueño de casa de su casa, sino que actúa de modo figurado para desterrar al sujeto de esa casa llamada "masculinidad dominante”. Él mismo empieza a dudar -”Toqué mi sexo y, con evidente alivio, comprobé que mi pene y mis testículos seguían en 
su sitio" (2003: 63)-, pero el asunto se plantea de modos mucho más hondos que los referidos al aparato reproductor. ${ }^{8}$ De hecho, para que el protagonista pueda reafirmarse como hombre, necesita descubrirse como mujer no sólo desde la transitividad del deseo, sino desde la conjunción de géneros ${ }^{9}$ e incluso, como se señala en la parte final con la denominación del hueso ilión, desde lo anatómico.

En varios momentos de la parte final de La cresta de Ilión se juega, aludiendo directamente al cuento "El patio cuadrado" de Dávila, con la sensación de ir marcha atrás -"Y entonces, sumido en la materia viscosa de las cosas indecibles, retrocedí. Y retrocedî" (2002: 101)-, lo que parece significar, por un lado, poner en reversa una existencia para ir hacia los recuerdos; pero, por otro, también irse aún más atrás, allí donde el lenguaje aún era un balbuceo y no existían las diferencias sexuales. Un tiempo en el que el "andrógino", según el planteamiento platónico, o la "disposición perversa polimorfa”, al decir de Freud, constituían el rasgo esencial de la identidad. Un espacio sin palabras donde la sexualidad era

${ }^{8}$ En su ensayo "El consumo textual y La cresta de Ilión de Cristina Rivera Garza" (2005), Emily Hind señala que: "En la última página, el protagonista admite que es mujer, aunque previamente disfrutó de su pene en relaciones sexuales. Se refiere al protagonista con el masculino por ser más conveniente para diferenciarle de las dos otras mujeres. Esta identidad inestable del protagonista se extiende a la joven Dávila, quien no se conoce y admite: 'no sé si soy o no Amparo Dávila' (139). Por esta indeterminación, Rivera impide que el público lector logre precisar el carácter de los personajes. Los aspectos centrales de $L a$ cresta de Ilión, entonces, abarcan la carencia de identidad estable, la carencia de una lógica esperada y la carencia de una trama resuelta" (Hind, 2005: 37).

9 "La primera vez que un hombre me provocó sensaciones tan íntimas y encontradas había sucedido muchos años atrás", recuerda la voz narrativa. "Recordé todo el incidente durante mi regreso a casa. Ocurrió durante los primeros años de la adolescencia, en ese período nebuloso en que el yo todavía no adquiere los candados de la costumbre o de los significados" (Rivera Garza, 2002: 113). 
potencia múltiple y no orientación: un Ilión primigenio al que hay que volver. "Desde ahí, desde Ilión, desde su cresta, Ulises partió de regreso a Ítaca después de la Guerra” (2002: 158), se lee en la última página de la novela. Desde ahí, desde el reconocimiento del hueso que identifica la sexualidad de una persona, es que se parte para señalar que no hay reconocimiento de género y no hay lenguaje que dé cuenta de ese género que se conciba separado de la escritura, ${ }^{10}$ cuestión que será tema, luego, de novelas tan deconstructivas como Lo anterior (2004) y La muerte me da (2007).

Domínguez Michael comenta que: "Como el título lo indica (y el lector lo sabrá al terminar la novela), el asunto de Rivera Garza es el sexo como piedra angular que va más allá del género, un misterio del que nuestros fantasmas dan el testimonio más duradero. La cresta de Ilión no bendice ni maldice a los espejos, culpables de la multiplicación de la especie, según Borges, sino que los interro-

${ }^{10}$ Sobre el vínculo entre género y literatura, y muy en la línea de la escritura transgresiva de autoras como Hélène Cixous, puede consultarse el texto de Rivera Garza “¿Ha estado usted alguna vez en el Mar del Norte?”, reproducido en la revista Debate feminista: "LO QUE MUJER UNO NO DICE: Soy la sombra que me persigue y el perseguimiento y el cuerpo y la sombra. LO QUE MUJER DOS CALLA: Lifting belly. Are you. Lifting. / Oh dear I said I was tender, fierce and tender. / Do it. What a splendid example of carelessness. / It gives me a great deal of pleasure to say yes. / Why do I always smile. / I don't know. / It pleases me. / You are easily pleased. / I am very pleased. / Thank you I am scarcely sunny. / I wish the sun would come out. / Yes. / Do you lift it. / High. / Yes sir I helped to do it. / Did you. / Yes. / Do you lift it. / We cut strangely. / What. / That's it. / Address it say to it hat we will never repent. / A great many people come together. / Come together. / I don't think this has anything to do with it. / What I believe in is what I mean. / Lifting belly and roses. / We get a great many roses. / I always smile. / Yes. / And I am happy. / With what. / With what I said. / This evening. / Not pretty. / Beautiful. / Yes beautiful. / Why don't you prettily bow. / Because it shows thought. / It does. / Lifting belly is strong. LO QUE MUJER TRES SE GUARDA: Si yo fuera hombre me andaría con cuidado. Si fuera mujer" (Rivera Garza, 2004: 70). 
ga"; para acabar señalando, acertadamente: "Dentro de dos o tres generaciones acaso alguien escribirá un texto que pregunte, ¿quién teme a Cristina Rivera Garza?” (2012: 112).

Lo esencial, entonces, más que el reconocimiento de Dávila en Rivera Garza es, para ello nos ha funcionado la deconstrucción, cómo esa escritura anterior disemina hospitalariamente a la tamaulipeca tanto en el nivel de su protagonista masculino como el nivel de su escritura. Y esa deconstrucción es inquietante, porque al cerrar el libro el temor, pues, del lector concreto ante la literatura de Rivera Garza, como el del médico frente la invasora y como el de Amparo Dávila falsa ante la Amparo Dávila verdadera, resulta el cuento más real.

\section{Bibliografía}

Bellatin, Mario,1999, Salón de Belleza, Tusquets, Barcelona.

Dávila, Amparo, 2001, Árboles petrificados, Planeta, México.

Derrida, Jacques, 1997, "Sobre la hospitalidad", entrevista en Staccato, programa televisivo de France Culturel, en Derrida en castellano. Disponible en: https://redaprenderycambiar.com.ar/ derrida/textos/hospitalidad.htm (Consultado: 14/V/2019).

Derrida, Jacques y Anne Dufourmantelle, 2000, La hospitalidad, Ediciones de La Flor, Buenos Aires. , 2005, Canallas. Dos ensayos sobre la razón, Trotta, Madrid.

Domínguez Michael, Christopher, 2007, Diccionario crítico de la literatura mexicana (1955-2005), FCE, México.

González Mateos, Adriana, 2003, La cresta de Ilión, Debate feminista, Revista del Centro de Investigaciones y Estudios de Género (CIEg) de la Universidad Nacional Autónoma de México, UNAM, vol. 27, pp. 341-344. 
Hind, Emily, 2005, "El consumo textual y La cresta de Ilión de Cristina Rivera Garza", Revista de Filología y Lingüistica de la Universidad de Costa Rica. vol. 31, núm. 1, pp. 35-50.

Iser, Wolfgang, 1987, "El acto de la lectura. Consideraciones previas sobre una teoría del efecto estético", en Dietrich Rall (comp.), En busca del texto: teoria de la recepción literaria, UNAM, México, pp. 121-143.

Kristeva, Julia, 1981, "Bajtin, la palabra, el diálogo y la novela”, Semiótica I, Fundamentos, Madrid, pp. 187-200.

Lachmann, Renate 2004, "Niveles del concepto de intertextualidad", en Desiderio Navarro (comp.), Intertextuälitat 1. La teoría de la intertextualidad en Alemania, Casa de las Américas/ unEAC, La Habana, pp. 15-24.

Mercado Gabriela, 2007, "Diálogo con Amparo Dávila y resolución de problemas de género en La cresta de Ilión de Cristina Rivera Garza", Revista de Humanidades del Tecnológico de Monterrey, núm. 22, pp. 45-75.

Palma, Alejandro y Cécile Quintana, 2015, "Introducción: Cristina Rivera Garza: Desde la situación de lo impropio", en Cristina Rivera Garza: una escritura impropia, Ediciones de Educación y Cultura, México, pp. 7-21.

Reynaud, Marise, 2012, "La cresta de Ilión o la refundación del lenguaje más allá de los "candados de la costumbre", Reviste Escritural. Écritures d'Amérique latine de la Universidad de Poitiers, núm 5. Disponible en http://www.mshs.univ-poitiers. $\mathrm{fr} / \mathrm{crla} /$ contenidos/ESCRITURAL/ESCRITURAL5/ESCRITURAL_5_SITIO/PAGES/Renaud.html. (Consultado: $14 / \mathrm{V} / 2019)$.

Rivera Garza, Cristina, 2002, La cresta de Ilión, Tusquets, Barcelona.

, 2004, “¿Ha estado usted en el Mar del Norte?”, Debate feminista. Revista del Centro de Investigaciones y Estudios de 
Género (CIEG) de la Universidad Nacional Autónoma de México, UNAM, vol. 29, pp. 66-82.

Saunero-Ward Verónica, 2006, "La cresta de Ilión: lo fantástico posmoderno", La palabra y el hombre, Universidad Veracruzana, núm. 137, enero-marzo, pp. 173-183.

Zaca Guevara María Reyna, 2005, Los cuentos de Amparo Dávila y La cresta de Ilión de Cristina Rivera Garza: un diálogo intertextual, Tesis de Maestría, BuAp, Puebla. 